\title{
The importance of central corneal thickness measurements and decision making in general ophthalmology clinics: a masked observational study
}

\author{
Ashish A Patwardhan*†, Mohammad Khan ${ }^{\dagger}$, Susan P Mollan ${ }^{\dagger}$ and \\ Paul Haigh ${ }^{\dagger}$
}

Address: Department of Ophthalmology, Shrewsbury and Telford Hospitals NHS Trust, Shrewsbury, UK

Email: Ashish A Patwardhan* - apatwa@hotmail.com; Mohammad Khan - drmikhan@gmail.com;

Susan P Mollan - soozmollan@doctors.org.uk; Paul Haigh - paul.haigh@rsh.nhs.uk

* Corresponding author †Equal contributors

Published: 20 january 2008

BMC Ophthalmology 2008, 8:I doi:I0.1 |86/|47|-24|5-8-I

This article is available from: http://www.biomedcentral.com/l47|-24/5/8/I

(C) 2008 Patwardhan et al; licensee BioMed Central Ltd.

This is an Open Access article distributed under the terms of the Creative Commons Attribution License (http://creativecommons.org/licenses/by/2.0), which permits unrestricted use, distribution, and reproduction in any medium, provided the original work is properly cited.

\begin{abstract}
Background: To assess the impact of knowing central corneal thickness (CCT) on glaucoma management in a United Kingdom district general hospital.

Methods: A masked observational non-interventional study included 304 eyes of 152 consecutive glaucoma cases attending general clinic. CCT was measured using a hand-held pachymeter. IOP, as measured by the Goldmann applanation tonometer (GAT), was adjusted for CCT using a normogram. Two identical study sheets were retrospectively constructed from each subject's case notes: one included the CCT and adjusted IOP information, the other excluded. Study sheets were randomly presented to a single masked observer to decide glaucoma management. The difference in management decision was noted.
\end{abstract}

Results: The mean \pm standard deviation CCT was $561.5 \pm 35.7 \mu \mathrm{m}, 538.9 \pm 41.4 \mu \mathrm{m}, 538.3 \pm 40.3$ $\mu \mathrm{m}$ for ocular hypertension (OHT), primary open angle glaucoma (POAG) and normal pressure glaucoma (NPG) subjects respectively. IOP adjustment was greater than $\pm 2 \mathrm{mmHg}$ in $33.9 \%(\mathrm{I03/}$ $304)$ of eyes. CCT and adjusted IOP information led to different treatment option in 37\%(55/152). Of the most important changes $20.4 \%(3 \mathrm{I} / \mathrm{I} 52)$ cases would have been commenced on additional IOP-lowering medication, $2.0 \%(3 / / 52)$ would have been counselled for trabeculectomy surgery and $3.3 \%(5 / 152)$ of the cohort would have been observed rather than treated.

Conclusion: CCT and adjusted IOP measurement can influence glaucoma management in a clinical context. It helps attribute risk and hence aids patient management decisions.

\section{Background}

Measuring intraocular pressure (IOP) is well established, with the Goldmann Applanantion Tonometer (GAT) being the most widely used device. The influence of corneal thickness on IOP by conventional tonometers was acknowledged by Goldmann [1] and clarified later by other investigators [2-6]. It has been recommended by many that GAT readings should be complimented with CCT measurements $[2,3]$. Normograms, based on varying CCT, exist for adjusting GAT readings in normal eyes [4- 
6]. There is much controversy regarding these scales and no single one has proven to be satisfactory as the relationship between IOP and CCT is variable $[3,7,8]$. What is certain is CCT measurement can allow for a more accurate estimate of the true IOP $[3,5]$ and as IOP is the main risk factor for the progression of glaucoma [9-11] using CCT in routine examinations seems mandatory.

Corneal thickness can aid classification in glaucoma suspects between primary open angle glaucoma (POAG), ocular hypertension (OHT) and normal pressure glaucoma (NPG) [12]. In addition measuring CCT was recommended by the ocular hypertension studies (OHTS) $[13,14]$ as it is a predictive factor for the conversion of OHT to POAG. Therefore knowledge of CCT can help to attribute the likelihood of disease progression and assigning the risk can change clinical management decisions to reach a personalized target pressure.

We believe CCT measurement is still not a routine part of eye examinations in some United Kingdom general clinics. The aim of this experiment was to analyse any change in management decisions based on a CCT measurement being revealed to a masked observer. This would help assess the influence of CCT measurements in decision making and gauge the importance of all general ophthalmology clinics having access to a pachymeter.

\section{Methods}

This observational non-interventional experiment studied 304 eyes of 152 consecutive patients who attended a general ophthalmologist's clinics with a diagnosis of glaucoma. For the purpose of this study only cases with NPG, POAG or OHT were included. They were classified in the following way: POAG was defined as IOP $\geq 22 \mathrm{mmHg}$, in presence of demonstrable visual field loss and/or significant optic disc cupping. While IOP $\leq 22 \mathrm{mmHg}$ with visual field loss and/or significant disc cupping cases were defined as having NPG. OHT was defined as IOP $\geq 22$ mmHg in the absence of visual field loss or significant optic disc cupping. Exclusion criteria included any cases below the age of 18 years, any subjects with ocular comorbidity such as previous corneal surgery or disease, any subjects with a diagnosis of secondary glaucoma, or where the diagnosis was unknown (i.e. glaucoma suspects).

Local ethics committee approval was obtained for this study. Measurements were only taken after informed consent was taken, and the tenets of the declaration of Helsinki were observed. Inclusion in the study was only after informed consent was taken. Subjects were routinely managed in clinic as normal. They consented for their case history to be reviewed, anonymised, summarised and that information to be used in this study. As is normal procedure in clinic IOP was measured using the GAT with top- ical proxymetacaine $0.5 \%$ and fluorescein (Bausch \& Lomb, Rochester, New York, USA) instilled into both eyes. The CCT measurements were recorded from a seated patient using a hand held ultrasonic pachymeter probe (Pachmate ${ }^{\mathrm{TM}}$ DGH 55, DGH Technology Inc, PA, USA) gently placed in the mid-pupillary axis of the cornea in the undilated eye. The Pachmate ${ }^{\mathrm{TM}}$ gives a mean value of CCT taken from 25 separate measurements. All measurements were taken by three senior ophthalmologists and both the tonometry and pachymetry were only taken once in each subject.

The IOP adjustment was made according to the manufacturer's logarithm which is based on Ehlers et al. [5], see Table 1 . All notes were retrospectively reviewed and summarised by 2 investigators. Two identical study sheets were then constructed: one included the CCT and adjusted IOP information, the other excluding these values (Figure 1 shows an example of a study sheet). The adjusted IOP value was made using the pachymeter manufacturer's algorithm which is based on a cannulation study done by Ehlers et al. [5].

Study sheets were shuffled and randomly presented to a single masked observer (PH) to decide glaucoma management. Using study sheets was an attempt to reduce any bias from memory effects of the assessor between cases. The investigators then recorded any differences in management decisions that had been noted by $\mathrm{PH}$.

Table I: Correction table used for adjusting IOP based on central corneal thickness (provided with Pachmate ${ }^{\mathrm{TM}}$ pachymeter and based on Ehlers et al [5]).

\begin{tabular}{cc}
\hline $\begin{array}{c}\text { Central Corneal Thickness } \\
\text { (Microns) }\end{array}$ & $\begin{array}{c}\text { Adjustment in IOP } \\
\text { (mm Hg) }\end{array}$ \\
\hline 445 & +7 \\
455 & +6 \\
465 & +6 \\
475 & +5 \\
485 & +4 \\
495 & +4 \\
505 & +3 \\
515 & +2 \\
525 & +1 \\
535 & +1 \\
545 & 0 \\
555 & -1 \\
565 & -1 \\
575 & -2 \\
585 & -3 \\
595 & -4 \\
605 & -4 \\
615 & -5 \\
625 & -6 \\
635 & -6 \\
645 & -7 \\
&
\end{tabular}




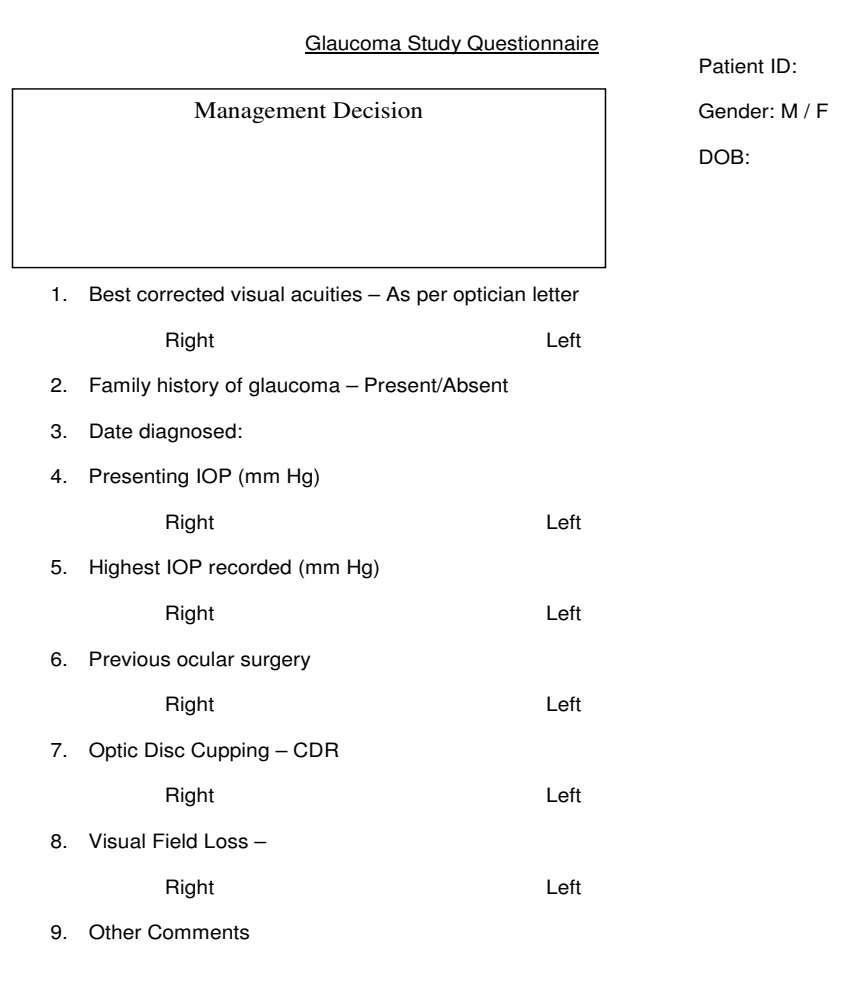

10. Pachymetry (performed with DGH instrument)

Right Left

11. Corrected IOP

Right Left

Figure I

Data collection sheet used in the study.

\section{Statistical analysis of data}

Excel (Microsoft Corporation, Redmond, WA, USA) was used to analyze and present data. The level of significance was chosen at $\mathrm{p}<0.05$.

\section{Results}

Of 152 patients studied, 84 were male and 68 were female. The mean age was 71.0 years $( \pm 11.5$ standard deviation years) POAG, OHT and NPG were classified in $49.3 \%$ (150/304), 34.9\% (106/304) and 15.8\% (48/304) of the cohort, respectively. The mean \pm standard deviation (SD) CCT of cohort was $546.7( \pm 40.7) \mu \mathrm{m}$. Mean CCT in the POAG group was $538.3( \pm 40.3) \mu \mathrm{m}$, OHT eyes it was $561.5( \pm 35.7) \mu \mathrm{m}$ and in NPG eyes it was $538.3( \pm 40.3)$ $\mu \mathrm{m}$. The difference between all three groups was statistically significant $(\mathrm{p}<0.0001$, ANOVA test).

Based on CCT readings, 33.9\% (103/304) had the IOP adjusted by greater than $\pm 2 \mathrm{mmHg}$. $18 \%$ (54/304) of eyes had the IOP reduced while $16.1 \%(49 / 304)$ had their IOP increased. Table 2 shows details of these adjustments
Table 2: A summary of IOP adjustment of more than $2 \mathrm{~mm} \mathrm{Hg}$ according to the diagnosis $(n=103)$

\begin{tabular}{cccc}
\hline & Total number & IOP reduced & IOP increased \\
\hline POAG & 50 & 19 & 31 \\
OHT & 38 & 29 & 9 \\
NPG & 15 & 6 & 9 \\
\hline
\end{tabular}

made in three groups while Figure 2 shows the distribution of the adjustment to be made to IOP

Analysis of change in management decision showed that the masked observer subsequently suggested different treatment in 36.2\% (55/152) of subjects based on CCT being made available. These differences were divided into 2 categories: when treatment was deemed to be insufficient and upgrading of treatment was suggested (undertreated group) and second, where it was deemed that subjects were over-treated, downgrading of treatment was suggested (over-treated group). Clinical outcomes of the decision change are shown in Table 3.

\section{Discussion}

Clinical decision-making relies on established and quantifiable parameters; these must be used rather than a reliance on medical impression and intuition. The importance of CCT is now well known and a proven parameter [13,14]. Shih et al. [15] had a similar objective: to ascertain whether CCT affected patient management. Their study, although set within a specialist glaucoma service, had similar results which showed that half their

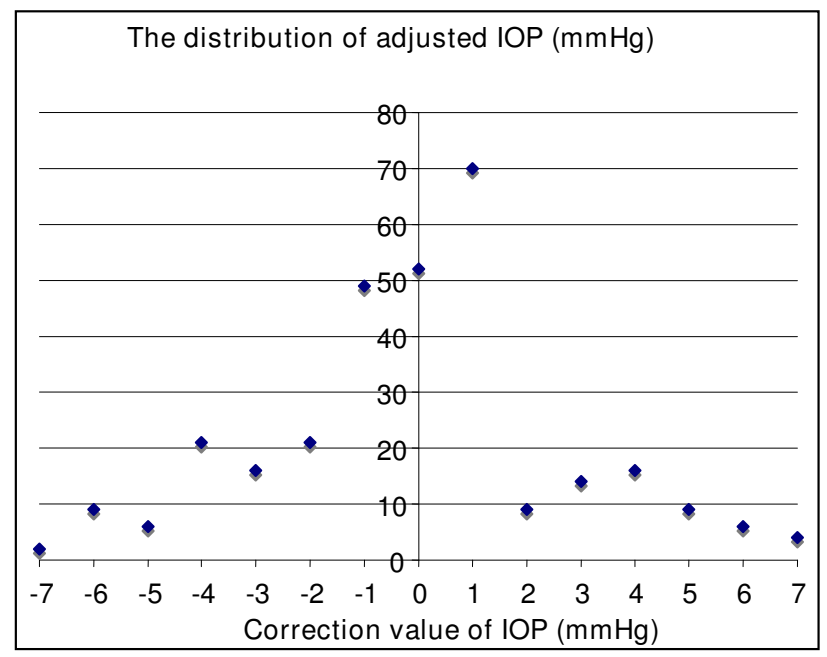

Figure 2

Chart showing the frequency of each level of IOP adjustment in the cohort, based on table I (correction of IOP by CCT [5]). 
Table 3: A summary of the change in treatment for both the under-and over-treated groups (total cohort $n=152$; change in management decision $n=55$ )

\begin{tabular}{ll}
\hline $\begin{array}{l}\text { Under-treatment group } \\
(\mathbf{n}=\mathbf{3 4 )}\end{array}$ & $\begin{array}{l}\text { Over-treatment group } \\
(\mathbf{n}=\mathbf{2 I})\end{array}$ \\
\hline 3 I cases would add additional IOP & II cases would discharge back to \\
Optician \\
3 cases would council for & $\begin{array}{l}5 \text { cases would observe rather } \\
\text { than treat } \\
\text { trabeculectomy }\end{array}$ \\
$\begin{array}{l}5 \text { cases would consider treatment } \\
\text { reduction }\end{array}$
\end{tabular}

study population required an adjustment of IOP \pm 1.5 $\mathrm{mmHg}$. What is interesting is that $8-10 \%$ of their cohort had a change in their medication, whereas we found nearly one third of ours would have had their treatment changed in light of the CCT and adjusted IOP measurement. This higher proportion may possibly reflect the difference in IOP correcting algorithm.

The use of normograms remains controversial. Gunvant et al. [16] compared three formulae, including Ehler's [5], and concluded that it and the others investigated (Orssengo-Pye) may significantly over estimate the effect of CCT on IOP measurement and lead to an overcorrection of IOP. It is possible that if the duplicate sheets had only contained CCT, instead of both CCT and IOP adjusted for CCT using Ehler's algorithm, the decision made could have been different. It would have relied on the single clinician's own intuition and knowledge, and not on a defined and quantifiable scale. Therefore we feel that although no single algorithm for correcting factors is well accepted; the use of such a scale was justified for this type of experiment.

While this study only tested one senior ophthalmologist's practice, it is clear from the results, that lack of one investigation or parameter such as CCT, can lead to a significantly different outcome for the individual patient: a 6 month review appointment changed to counseling for trabeculectomy surgery in $2 \%$ of the cohort. Being a theoretical experiment is a limitation of this study: it could be argued that the decision maker (PH) was in an artificial situation where patients were not actually involved, and this could possibly change his actual decision. However the aim of the study was to provide evidence that knowledge of CCT changed management decisions and in 36\% of the cohort it did. Although only one reading of CCT was taken in this study we are aware that it has been suggested that more than one CCT measurements are required, as there can be a significant difference between measurements taken at different times from the same eye [17].

\section{Conclusion}

Implementation of routine central corneal thickness measurement could change patient management in the general ophthalmologist's practise. We feel that a pachymeter is an essential item of the ophthalmic equipment armamentarium. The cost of such an item to a department is small compared to being able to confidently relax or step up a patient's follow-up or treatment.

CCT is one factor that is necessary to adjust IOP to achieve a more accurate IOP and it allows monitoring for the risk of progression to be more precise. Any decision in glaucoma, in the absence of CCT is an uninformed one.

\section{Competing interests}

The author(s) declare that they have no competing interests.

\section{Authors' contributions}

$\mathrm{AP}, \mathrm{MK}$ and $\mathrm{PH}$ conceived and conducted the study. AP and SPM analyzed the study and contributed to the writing of the manuscript. All authors read and approved the final manuscript.

\section{Acknowledgements}

Previously presented at the European Society of Cataract and Refractive surgeons (ESCRS) annual meeting (London), September 2006

\section{References}

I. Goldmann H, Schmidt T: Uber applanationstonometries. Ophthalmologica 1957, 134:221-242.

2. Whitacre MM, Stein R: Sources of error with use of Goldmanntype tonometers. Surv Ophthalmol 1993, 38: I-30.

3. Doughty MJ, Zaman ML: Human corneal thickness and its impact on intraocular pressure measures: a review and meta-analysis approach. Surv Ophthalmol 2000, 44(5):367-408.

4. Whitacre MM, Stein RA, Hassanein K: The effect of corneal thickness on applanation tonometry. Am J Ophthalmol 1993, I I:592-596.

5. Ehlers N, Bramsen T, Sperling S: Applanation tonometry and central corneal thickness. Acta Ophthalmol (Copen) 1975, 53:34-43.

6. Stodtmeister R: Applanation tonometry and correction according to corneal thickness. Acta Ophthalmol Scand 1998, 76:319-324.

7. Lewis RA: Refractive surgery and the glaucoma patient: customized corneas under pressure. Ophthalmol 2000, 107:1621-1622.

8. Kniestedt C, Lin S, Choe J, Bostrom A, Nee M, Stamper RL: Clinical comparison of contour and applanation tonometry and their relationship to pachymetry. Arch Ophthalmol 2005, I 23:1532-1537.

9. Leske MC: The epidemiology of open-angle glaucoma: a review. Am J Epidemiol 1983, I | 8: |66-I9|.

10. Heijl A, Leske MC, Bengtsson B, Hyman L, Bengtsson B, Hussein M, Early Manifest Glaucoma Trial Group: Reduction of intraocular pressure and glaucoma progression: results from the Early Manifest Glaucoma Trial. Arch Ophthalmol 2002, I 20(10): | 268-79.

II. Leske MC, Heijil A, Hussein M, Bengtsson B, Hyman L, Komaroff E, Early Manifest Glaucoma Trial Group: Factors for glaucoma progression and the effect of treatment: the early manifest glaucoma trial. Arch Ophthalmol 2003, I 2 I(I):48-56.

12. Shah S, Chatterjee A, Mathai M, Kelly SP, Kwartz J, Henson D, McLeod D: Relationship between corneal thickness and meas- 
ured intraocular pressure in a general ophthalmology clinic. Ophthalmology 1999, 106(II):2154-60.

13. Kass MA, Heuer DK, Higginbotham EJ, Johnson CA, Keltner JL, Miller JP, Parrish RK II, Wilson MR, Gordon MO, for the Ocular Hypertension Treatment Study Group: The Ocular Hypertension Treatment Study: a randomized trial determines that topical ocular hypotensive medication delays or prevents the onset of primary open-angle glaucoma. Arch Ophthalmol 2002, 120:70|-7|3.

14. Gordon MO, Beiser JA, Brandt JD, Heuer DK, Higginbotham EJ, Johnson CA, Keltner JL, Miller JP, Parrish RK II, Wilson MR, Kass MA, for the Ocular Hypertension Treatment Study Group: The Ocular Hypertension Treatment Study: baseline factors that predict the onset of primary open-angle glaucoma. Arch Ophthalmology 2002, 1 20:7|4-720.

15. Shih CY, Graff-Zivin JS, Trokel SL, Tsai JC: Clinical significance of central corneal thickness in the management of glaucoma. Arch Ophthalmol 2004, I 22: I 270-। 275.

16. Gunvant P, O'Leary DJ, Baskaran M, Broadway DC, Watkins RJ, Vijava $\mathrm{L}$ : Evaluation of tonomeric correction factors. I Glaucoma 2005, I4(5):337-43.

17. Wickham L, Edmunds B, Murdoch IE: Central corneal thickness: will one measurement suffice? Ophthalmology 2005, I I 2(2):225-8.

\section{Pre-publication history}

The pre-publication history for this paper can be accessed here:

http://www.biomedcentral.com/1471-2415/8/1/prepub

Publish with Biomed Central and every scientist can read your work free of charge

"BioMed Central will be the most significant development for disseminating the results of biomedical research in our lifetime. "

Sir Paul Nurse, Cancer Research UK

Your research papers will be:

- available free of charge to the entire biomedical community

- peer reviewed and published immediately upon acceptance

- cited in PubMed and archived on PubMed Central

- yours - you keep the copyright

Submit your manuscript here:

http://www.biomedcentral.com/info/publishing_adv.asp 